„Kwartalnik Filmowy” nr 109 (2020)

ISSN: 0452-9502 (Print) ISSN: 2719-2725 (Online)

https://doi.org/10.36744/kf.264

(c) Creative Commons BY-NG-ND 4.0

\title{
Tomasz Kłys
}

Uniwersytet Łódzki

http://orcid.org/oooo-0oo1-7443-9479

\section{O subiektywizacji w filmie raz jeszcze}

\author{
Slowa kluczowe: \\ narracja filmowa; \\ subiektywizacja; \\ fokalizacja
}

\begin{abstract}
Abstrakt
W książce Podwójna perspektywa. O subiektywizacji zapośredniczonej w filmie (2019) Robert Birkholc omawia problematykę zastosowania w filmie fabularnym funkcjonalnego ekwiwalentu literackiego chwytu mowy pozornie zależnej. Temat ten autor rzutuje na tło zagadnienia subiektywizacji w filmie fabularnym, przywołując historię technik subiektywizacyjnych w historii kina i historyczny zarys tej problematyki w badaniach filmoznawczych. Ekwiwalent ten zostaje nazwany subiektywizacją zapośredniczoną. Opisanie tej kategorii jest możliwe na tle refleksji nad relacjami między perspektywą instancji narracyjnej a perspektywą postaci przedstawionej. Autor wykorzystuje przejęte z teorii literatury kategorie fokalizacji zewnętrznej i wewnętrznej. Decydująca jest kategoria fokalizacji wewnętrznej i jej podział na narratywizację, personifikację i subiektywizację. W drugiej części pracy autor demonstruje przydatność przywołanych i wypracowanych przez siebie narzędzi pojęciowych w drobiazgowych analizach pięciu filmów, których formalną dominantą jest subiektywizacja zapośredniczona.
\end{abstract}




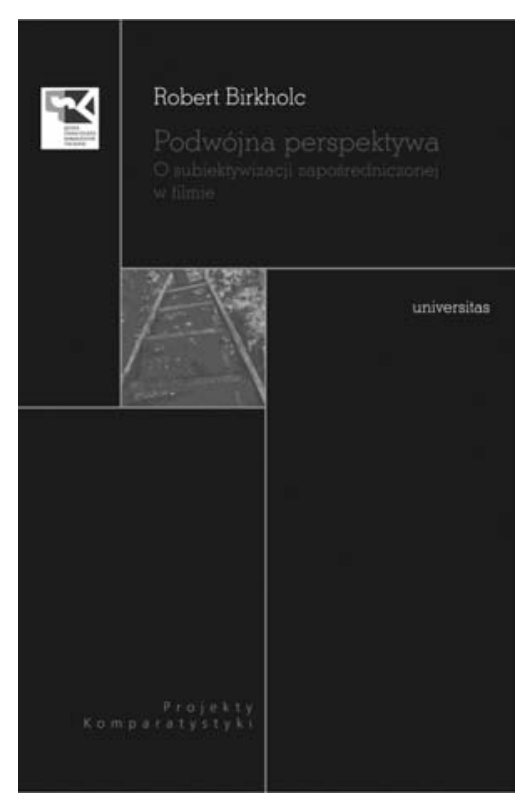

Książka Roberta Birkholca Podwójna perspektywa. O subiektywizacji zapośredniczonej w filmie ma wszystkie zalety, które powinny charakteryzować intelektualnie inspirującą rozprawę naukową z humanistyki: trafne znalezienie nieopisanego dotąd szerzej obszaru badań, horyzont intelektualny, wyrażający się choćby $\mathrm{w}$ bogatej literaturze i umiejętnym jej stosowaniu, precyzję pojęciowa ciekawość poznawcza, klarowność logiczną i - last but not least - stylistyczną elegancję wywodu. Do tego wykazu dodałbym jeszcze odwagę autora - we współczesnej teorii filmu panuje „literaturofobia", nieomal nakazująca badaniom nad filmem rezygnację z narzędzi, metod i pojęć wypracowanych przez teorię literatury. Tendencja emancypacyjna, poniekąd zrozumiała $\mathrm{w}$ kontekście dążenia do autonomii i określenia differentiae specificae dziedziny, doprowadziła po latach do nadmiernego chyba uzależnienia filmoznawstwa od socjologii i antropologii, i zapominania o tym, że są one czyimiś w y powied zi a mi, domagającymi się hermeneutyki tekstami i zazwyczaj też dziełami artystycznymi, potrzebującymi opisu, analizy i interpretacji ich formy. Birkholc, wychodząc od pewnej kategorii teoretycznoliterackiej, nie jest bynajmniej naiwny i anachroniczny - znajduje funkcjonalny ekwiwalent tej kategorii, znakomicie opisuje jego modus faciendi w korpusie konkretnych dzieł filmowych, a jednocześnie prezentuje formę, styl i chwyty artystyczne, które go konstruują.

Kategoria, która zainspirowała autora, jest mowa pozornie zależna, chwyt narracyjny znany zarówno z klasycznej powieści realistycznej, jak i - a może przede wszystkim - z literatury modernizmu. Jak wiadomo, w mowie pozornie zależnej dochodzi do nakładania się dwóch perspektyw: instancji narracyjnej (jest ona formalnym podmiotem dyskursu w miejscu zastosowania tego chwytu) i postaci przedstawionej (jej faktyczny "głos" czy „punkt widzenia" dominuje, choć ona sama formalnie nie jest podmiotem narracji w danym ustępie tekstu). Birkholc rzeczowo i rzetelnie przedstawia historię oraz rozmaite funkcje, jakie może pełnić mowa pozornie zależna w literaturze, zwracając szczególną uwagę na funkcjonalność w analizie tego typu narracji kategorii fokalizacji - wewnętrznej (od postaci) i zewnętrznej (od instancji narracyjnej). Wśród najistotniejszych funkcji tego typu narracji autor wymienia reprezentację toku myślowego, percepcji, doświadczenia i horyzontu społeczno-kulturowego postaci, i jednoczesny ich rozziew z horyzontem czy światopoglądem instancji narracyjnej.

Autor ma świadomość nieprzekładalności osadzonej w języku kategorii mowy na zupełnie odmienny system semiotyczny czy też zupełnie inne medium, jakim jest audiowizualne, choć przede wszystkim wizualne, medium filmowe. Toteż problematykę funkcjonalnego ekwiwalentu mowy pozornie zależnej w filmie wiąże z zagadnieniem subiektywizacji w fabule, przywołując przy okazji zarówno historię technik subiektywizacyjnych $w$ historii kina, jak i historyczny zarys tej problematyki w badaniach filmoznawczych. Po czym rozważa kwestię funkcjonalnego ekwiwalentu mowy pozornie zależnej, nazywając go subiektywizacją zapośredniczoną. Opisanie tej kategorii jest moż- 
liwe na tle refleksji nad relacjami między perspektywą instancji narracyjnej a perspektywą postaci przedstawionej. Oczywiście, muszą tu powrócić, już bez terminologicznej adaptacji, kategorie fokalizacji zewnętrznej i wewnętrznej. Decydująca jest kategoria fokalizacji wewnętrznej i jej - kapitalny i wart rozpropagowania w badaniach filmoznawczych - podział na narratywizację, personifikację oraz subiektywizację.

W wypadku narratywizacji mamy do czynienia z narratorami formalnymi, czyli postaciami opowiadającymi. Personalizacja polega na zbliżeniu perspektywy zewnętrznej do perspektywy postaci, choć formalnie postać wciąż jest ukazywana przez narrację z zewnątrz. W przypadku subiektywizacji - pisze Birkholc - uzyskujemy głębszy wglad w perspektywe bohatera niż $w$ personalizacji, ponieważ reprezentacji poddane zostaja jego stany $i$ odczucia - percepcja, emocje, sny czy halucynacje. Nie jest to podział rozłączny: różne typy fokalizacji często ze soba wspótistnieja, a granice między nimi sa nieostre (s. 90). Oczywiście w subiektywizacji stopień wewnętrznej fokalizacji jest znacznie wyższy niż w przypadku personalizacji: doświadczamy wówczas świata nie tyle „z postacią” (jak w personalizacji), ile „poprzez nią”, gdyż postać jest tu podmiotem percepcji, a narracja zostaje przefiltrowana przez jej perspektywe (s. 96). To nie koniec dystynkcji autora - subiektywizacja może mieć postać werbalna, jak i szczególnie istotną w filmie, niewerbalna, a ta ostatnia - postać subiektywizacji stylistycznej i niestylistycznej. Ale jeszcze istotniejszy jest podział na subiektywizację be zpośrednią (daną nam np. przez strumień świadomości czy ujęcia z punktu widzenia) i subiektywizację zapośredniczona, w której dochodzi do wyrazistej interferencji fokalizacji wewnętrznej (dominującej, osadzającej nas w perspektywie postaci) z fokalizacją zewnętrzną, na skutek czego struktura narracji implikuje obecność innego podmiotu, uwydatnia mediację instancji z pewnego „wyższego" poziomu. I to właśnie ta subiektywizacja zapośredniczona, zwłaszcza jako subiektywizacja stylistyczna, jest poszukiwanym ekwiwalentem literackiej mowy pozornie zależnej oraz przedmiotem drobiazgowego rozbioru w przedstawionych w rozdziałach 4-8 analizach konkretnych dzieł filmowych.

Muszę stwierdzić, że problematyzacja zagadnienia i logika wywodu są w pierwszej, stricte teoretycznej części pracy bez zarzutu, a precyzja i klarowność pojęciowa budzą szczery podziw. Wprowadzane terminy i kategorie nie są jakąś zbędną komplikacją pojęciowa, z którą powinna się uporać brzytwa Ockhama; przeciwnie, może nieco zawile brzmiące pojęcia, czy to zaczerpnięte od innych teoretyków (jak fokalizacja), czy wypracowane przez samego autora (jak subiektywizacja zapośredniczona), istotnie zdają się najtrafniej ujmować zawiłą problematykę, a zaprezentowane przez autora omówienia filmów udowadniają ich funkcjonalność i operacyjną skuteczność w analizie i interpretacji dzieł.

Druga, analityczna część pracy dobitnie demonstruje przydatność przywołanych i wypracowanych przez Roberta Birkholca narzędzi pojęciowych. Analizy pięciu filmów czyta się z niemałą przyjemnością, a dzięki sprawności warsztatowej autora w opisie formy filmowej, zwłaszcza chwytów stylistycznych konstytuujących subiektywizację zapośredniczona, omawiane dzieła jawią się czytelnikowi rozprawy bardzo wyraziście, dzięki czemu nie musi on widzianych przed laty filmów oglądać na nowo. W centrum każdej analizy znajduje się refleksja nad stylistycznym sposobem reprezentacji (przez subiektywizację zapośredniczoną) osobowości głównego bohatera filmu. W Palaczu zwłok (Spalovac mrtvol, 1968) Juraja Herza tytułowa postać to nekrofil, biedermeierowski mieszczuch, zgłaszający ostatecznie akces do nazizmu, a narracja filmu przez subiektywizację zapośredniczoną przedstawia jego skandaliczne, nieuświadomione pragnienia i popędy. Marcello Clerici, bohater Konformisty (Il Conformista, 1970) Bernardo Bertolucciego, z własnej woli wiąże się z włoskim faszyzmem, powodowany pragnieniem ukrycia swej „inności” przez manifestację „,normalności”, za którą błędnie bierze alians z totalitarną władzą. Akces ten pogłębia 
jednak tylko alienację bohatera, a po upadku reżimu jego wewnętrzny chaos powraca ze zdwojoną siłą. Grzegorz Królikiewicz portretuje w Tańczacym jastrzębiu (1977) modelowego dla PRL reprezentanta nowej, „socjalistycznej” inteligencji o chłopskich korzeniach, ukazując przez frapujące rozwiązania narracji „subiektywnej zapośredniczonej” niedopasowanie bohatera do miejskiego otoczenia oraz cenę, jaką płaci on za gwałtowne i dobrowolne wykorzenienie z własnego środowiska. Mickey i Mallory, tytułowi „urodzeni mordercy” z filmu Olivera Stone'a (Natural Born Killers, 1994), popełniają swe szokujące zbrodnie, żyjąc swoistą ,jjaźnią odzwierciedloną", ukształtowaną przez mass media, zwłaszcza telewizję. Zsubiektywizowana narracja filmu reprezentuje tę kulturowo ukształtowaną perspektywę postaci. Na koniec analiza filmu Darrena Aronofsky'ego Requiem dla snu (Requiem for a Dream, 2000) przynosi opis reprezentacji intensywnych doświadczeń cielesnych bohaterów tego filmu, powodowanych przez narkotyki, tabletki psychoaktywne, kurację odchudzającą i seks. Doświadczenia te wiodą do klęski marzeń i fizycznej autodestrukcji postaci, a dokonany przez autora opis oczywiście uwypukla ich przedstawienie za pomocą środków stylistycznych z repertuaru subiektywizacji zapośredniczonej.

Analizy te - podkreślę jeszcze raz - są znakomite i naprawdę odkrywcze. Autor odsłania, nazywa i interpretuje aspekty, które przy zwyczajnym, nie-analitycznym oglądzie owych filmów są odczuwane jedynie intuicyjnie i powierzchownie. Mógłbym z autorem dyskutować tylko o doborze tytułów. Rzecz w tym, że analizowane utwory są w jakimś sensie do siebie podobne. Akcja Palacza zwłok, Konformisty i Tańczacego jastrzębia rozgrywa się w rzeczywistości społeczeństw państw totalitarnych, a bohaterowie pierwszych dwóch filmów to dodatkowo osobowości perwersyjne i neurotyczne (w odniesieniu do bohatera czeskiego filmu można wręcz mówić o psychozie, podobnie zresztą jak w przypadku „urodzonych morderców" z filmu Stone'a). Bohaterowie wszystkich pięciu dzieł są zdecydowanie odpychający, każąc widzowi dystansować się od ich doświadczeń i postrzegania świata; to zresztą rezultat mediatyzacji subiektywizacji przez nadrzędną instancję narracyjną. Moim zdaniem w tej mediatyzacji dystans meta-instancji graniczy wręcz z mizantropia przynajmniej w odniesieniu do głównych bohaterów filmów. Może to dawać poczucie, że poetyka subiektywizacji zapośredniczonej jest skorelowana z przedstawianiem postaci zasadniczo negatywnych, w każdym razie takich, wobec których nieodzowny jest krytyczny dystans (wydaje się, że sam autor ma tego świadomość - świadczy o tym jego uwaga, że ta forma subiektywizacji sprzyja kreowaniu podmiotów szczególnego rodzaju: niestabilnych /s. 306/, niedookreślonych, wieloznacznych, czasem wewnętrznie sprzecznych). Wszystkie filmy analizowane w drugiej części książki reprezentują też zbliżony paradygmat estetyczny: są to filmy post-klasyczne, które można by z grubsza zakwalifikować jako modernistyczne lub postmodernistyczne.

Na szczęście ten nieco jednostronny dobór filmów i typ bohaterów jest częściowo zrównoważony rysem historycznym w pierwszej części książki, prezentującej w zwięzły i syntetyczny sposób historię technik subiektywizacyjnych w kinie, z zaakcentowaniem zwłaszcza arcydzieł kina weimarskiego (Gabinet doktora Caligari, Nerwy, Portier z hotelu Atlantic) i francuskiego impresjonizmu filmowego (Szaleństwo doktora Tube, Napoleon, Uśmiechnięta pani Beudet, La Glace à trois faces), których rola w wypracowaniu rozmaitych środków wyrazu dla wyrażenia subiektywności postaci jest nie do przecenienia. A krótkie, lecz bardzo wnikliwe i warsztatowo sprawne analizy dwóch dzieł, kina niemego Portiera $z$ hotelu Atlantic (1924) Friedricha Wilhelma Murnaua i Napoleona (1927) Abla Gance'a, unaoczniaja, że „podwójna perspektywa” niekoniecznie musi ujmować osobowość „nienormalną” - możemy też przez nią spoglądać na „zwykłego człowieka” czy wielką postać historyczną, jak $\mathrm{w}$ wymienionych przykładach. 
Reasumując - odkrywcza, zajmująca w lekturze i świetnie napisana książka Roberta Birkholca demonstruje, że teoria filmu inspirowana teorią literatury nie powiedziała jeszcze ostatniego słowa.

Robert Birkholc, Podwójna perspektywa. O subiektywizacji zapośredniczonej w filmie, Universitas, Kraków 2019

\begin{tabular}{l|l} 
Tomasz Kłys & $\begin{array}{l}\text { Filmoznawca, absolwent kulturoznawstwa na Uniwersytecie Łódz- } \\
\text { kim, obecnie profesor Uniwersytetu Łódzkiego i pracownik Katedry }\end{array}$ \\
& Filmu i Mediów Audiowizualnych tejże uczelni. Obszarem jego za- \\
& interesowań badawczych jest m.in. filmowa narratologia, teoria die- \\
& gezy oraz kino niemieckie z okresu Republiki Weimarskiej i Trzeciej \\
& Rzeszy. Autor książek: Film fikcji i jego dominanty (1999), Dekada dok- \\
& tora Mabuse (2006), Od Mabusego do Goebbelsa (2013), współautor \\
& (wraz z E. Nurczyńską-Fidelską, P. Sitarskim i K. Klejsą) podręcznika \\
& Kino bez tajemnic (2009).
\end{tabular}

\section{Bibliografia}

Birkholc, R. (2019). Podwójna perspektywa. O subiektywizacji zapośredniczonej w filmie. Kraków: Universitas.

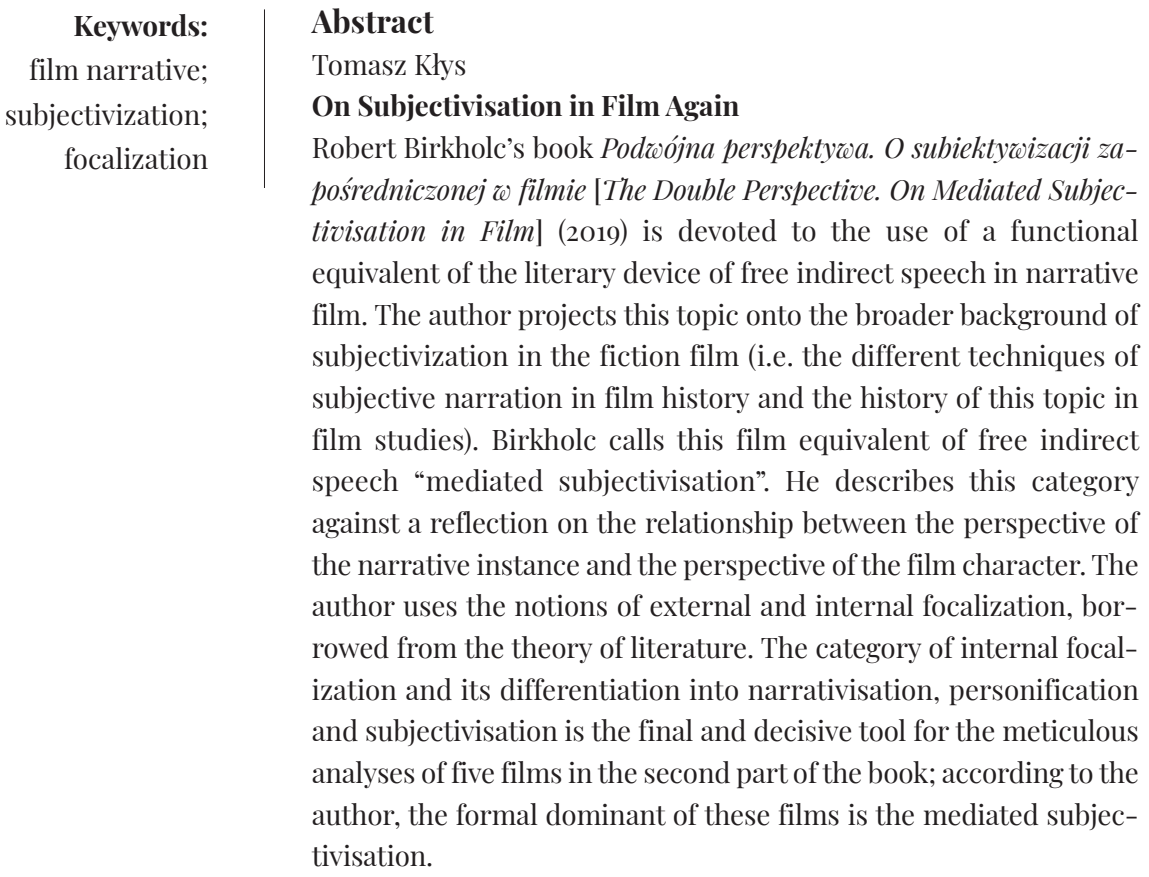

